\title{
ESCALAS DA AÇÃO POLÍTICA E MOVIMENTOS SOCIAIS: O CASO DO MOVIMENTO NEGRO BRASILEIRO E A EMERGÊNCIA DE POLÍTICAS EDUCACIONAIS DE COMBATE AO RACISMO
}

\author{
INTI MAYA SOETERIK ${ }^{1}$ \\ Universidade de Amsterdã \\ RENATO EMERSON NASCIMENTO DOS SANTOS ${ }^{2}$ \\ Universidade Estadual do Rio de Janeiro
}

Resumo: Recentemente a temática racial tem se tornado base da construção de políticas educacionais no Brasil, país que sempre negou a existência do racismo e construiu seu ideário de nação representando-se como uma "democracia racial". Cotas nas universidades, políticas de produção de conhecimento e a inserção e revisão de conteúdos no currículo escolar são alguns exemplos. O artigo debate os processos políticos que vêm impulsionando tais mudanças, tensionando a relação entre atores e processos globais e o protagonismo do Movimento Negro brasileiro. Seriam tais políticas decorrentes de forças imperialistas pautando agendas no Brasil ou de uma "política de escalas" do Movimento Negro, que mobiliza atores, arenas e instrumentos em diferentes escalas de modo a fortalecer suas lutas e construir políticas públicas?

Palavras-chave: Raça; Políticas educacionais; Movimento Negro; Escala; Escalas da política; Política de escalas.

\footnotetext{
${ }^{1}$ Educadora, doutora em Educação e Desenvolvimento e professora da Universidade de Amsterdam. Contato: i.m.soeterik@uva.nl.

${ }^{2}$ Geógrafo, doutor em Geografia e professor da Universidade do Estado do Rio de Janeiro. Contato: renatoemerson@ hotmail.com.
} 
SCALES OF POLITICAL ACTION AND SOCIAL MOVEMENTS: THE CASE OF BRAZILIAN BLACK MOVEMENT AND THE EDUCATIVE POLICIES AGAINST RACISM

\begin{abstract}
Recently, race issues have become point of departure for the construction of educational policies in Brazil (a country which always denied the existence of racism and constructed its idea of a nation representing itself as a "racial democracy"). Quotas on universities, politics of knowledge production and the insertion and revision of contents in school curricula are some examples of these policies. The questions addressed in this article are: is it a global process, or would it be the historical protagonist role of the Brazilian Black Movement that determines the reinforcement of this agenda on national scale? Is this process about the "disembedding" of scales of politics, or is it about the Black Movement's "politics of scales" - which mobilizes actors, arenas and instruments on different scales in order to strengthen its struggle and to construct public policies?
\end{abstract}

Keywords: Race, Education policy; Brazil; Black Movement, Multi-scalarity, Politics of scales.

\title{
Introdução
}

$\mathrm{Na}$ última década emergiram no Brasil políticas de combate ao racismo e às desigualdades raciais, em diversos campos, com visível destaque para a Educação. O país, durante grande parte do século XX, se afirmou oficialmente como uma sociedade da "democracia racial" e tais políticas aparecem como (ou a partir de) uma negação desta ideia. Qual a relação entre essa emergência no cenário nacional e processos globais de construção e difusão de agendas, inclusive educacionais?

Um dos debates mais acalorados na emergência recente de políticas públicas baseadas em raça no Brasil é sobre o papel dos processos e agentes internos e externos na construção de uma agenda racial. Uma explicação já antiga no país (como parte da própria ideologia da democracia racial) afirma que estas políticas, chamadas de "ação afirmativa", são fruto de cópia ou importação artificial de uma pauta vinda dos EUA, e que não encontra vínculos com a realidade das relações raciais brasileiras.

Essa explicação também aparece no famoso artigo intitulado $A s$ artimanhas da razão imperialista, de Pierre Bourdieu e Loïc Wacquant, de 2002. Estes autores apontam o imperialismo estadunidense (através das fundações e agências de cooperação) como um vetor de exportação de agendas, transplantando uma compreensão das relações raciais norteamericanas, que seria então incompatível com o padrão histórico 
desenvolvido no Brasil, onde "raça" não faz sentido. Estes argumentos encontram ecos no pensamento social brasileiro, e têm grandes repercussões no debate nacional, pelo prestígio intelectual dos autores e por oferecer uma linha de raciocínio explicativa de como agendas, atores e processos internacionais se impõem (e, são impostos) sobre agendas, atores e processos intranacionais.

Propomos aqui duas críticas a tal leitura. Primeiramente, mais do que uma importação imperialista, a construção da agenda racial no Brasil nos remete a uma reflexão sobre os processos de articulação de escalas (compreendidas aqui como campos, arenas e as esferas de poder em que o exercício político define projetos, práticas e usos do/no território), mas indicando certa relação de primazia entre elas: o global (o imperialismo americano) se impondo através de suas "artimanhas" ao nacional. Ou seja, as escalas são vistas como "níveis" distintos, separados, com lógicas independentes e com uma relação hierárquica entre elas. Nesse sentido, propomos uma reflexão sobre o conceito de escala. Segundamente, tal leitura supervaloriza o papel dos organismos internacionais (os chamados "atores globais") e ignora a existência de uma luta histórica de movimentos sociais, no caso, do Movimento Negro no Brasil - como se este não fosse protagonista na ascensão de políticas de raça.

Propomos aqui uma leitura escalar desses processos, mas, uma interpretação que não opere a partir de hierarquias, nem entre escalas (do global sobre o nacional, ou sobre o local), nem entre atores sociais. Acreditamos que uma leitura espacial dos processos políticos de construção das agendas deve partir da ação. Neste sentido, uma geografia da ação, aqui centrada no suporte conceitual da escala (compreendida numa concepção política), nos auxilia ao entendimento da emergência de políticas de combate ao racismo no Brasil contemporâneo, e em particular, no campo da educação. Como atores sociais mobilizam o ordenamento escalar dos jogos políticos, efetuam políticas de escalas, dialogam com atores, eventos e processos em diferentes escalas para promover suas lutas e transformações sociais?

Para dar cabo desses objetivos, iniciaremos explicando a abordagem do conceito de escala adotado no presente artigo, sublinhando a importância de uma compreensão multi e interescalar dos processos políticos na investigação da ascensão de políticas públicas baseadas em raça no Brasil. $\mathrm{Na}$ seção seguinte, o foco será direcionado à discussão sobre a emersão da agenda pública nacional contra as desigualdades raciais no Brasil, oferecendo um breve panorama histórico. Para mostrar o papel protagonista 
do Movimento Negro Brasileiro em diferentes escalas, será introduzido o conceito de área de movimento. Em seguida, examinaremos criticamente a relação entre a emergência da temática racial nas políticas públicas no Brasil e a agenda global. A Conferência Mundial contra o Racismo, Discriminação Racial, Xenofobia e Intolerância Correlata, ocorrida em Durban (África do Sul, 2001) será discutida como exemplo da mobilização pelo Movimento Negro Brasileiro, de uma "política de escalas". Este exemplo ajudará a compreender o argumento de que a inserção da temática racial nas agendas políticas (educacionais) brasileiras, ainda que estimulada por processos globais como os envolvidos na Conferência de Durban, deve ser compreendida primeiramente como um processo no qual o Movimento Negro Brasileiro desempenha papel protagonista em diversas escalas. Para teste de tal hipótese, analisamos também a incorporação da temática racial em documentos e propostas para o Brasil (a partir da década de 1990) de um dos mais influentes organismos internacionais, o Banco Mundial. Na seção de conclusão, tentando responder à questão de ser um processo ou ator global, ou o papel histórico de protagonista do movimento social que determina o fortalecimento de uma agenda antirracismo na escala nacional, discutiremos a aplicabilidade, no caso em tela, de conceitos como efeito bumerangue (boomerang effect), curto circuito, salto escalar (jumping scales) e encaixe-desencaixe de escalas da política.

\section{1 - Processos multiescalares e a definição de agendas políticas}

A escala é um conceito que está no centro da compreensão do mundo atualmente. $\mathrm{O}$ uso quase onipresente da ideia de globalização para explicar fenômenos e processos nas mais variadas áreas traz a escala para o centro das narrativas. A própria ideia de globalização já é uma narrativa de base escalar, que aponta para a redefinição escalar de processos. Quando se propõe a ideia de "pensar global e agir no local", é a redefinição de relações escalares na organização de estratégias e ações que está colocada.

Cada vez mais, portanto, se fala das relações entre global, regional, nacional, local, para compreender processos e transformações em período recente. Isso coloca, entretanto, algumas questões. A forma como se compreende o próprio conceito de escala tem um grande peso na construção das explicações sobre fenômenos. Há uma tendência corrente a se operar com uma leitura dissociada de escalas preconcebidas e reificadas, que se articulam hierarquicamente. 
A visão tradicional do ordenamento escalar do mundo, baseada em relações de contiguidade, hierarquia e articulação, preconizava que um conjunto de lugares formava uma região, um conjunto de regiões formava um país, um conjunto de países formava um continente e um conjunto de continentes formava o mundo. A imagem emergente era sempre de alguma forma semelhante: conjuntos ou entidades espaciais se articulando/unindo, constituindo novos conjuntos ou entidades, em outra escala. Cada escala correspondia a um "nível de agregação", passível de identificação sempre que a problemática ou fenômeno observado sofria consideráveis mutações pela redefinição de dimensão do recorte espacial. Tal representação conduz à percepção destes níveis de agregação, que são as escalas pensadas como "patamares espaciais" articulados, mas em essência diferenciados e dissociados. Isso porque a metáfora do nível (enquanto sobreposição vertical de diferentes planos horizontais) constrói a imagem da hierarquia entre as escalas espaciais: cada nível é composto pela soma e encaixe dos recortes territoriais em escala imediatamente inferior em termos da área abrangida, preconizando também uma relação de subordinação e hierarquia nas relações entre escalas. Esse mundo aparecia, então, como resultado do "encaixe" de escalas.

$\mathrm{O}$ que vem sendo mostrado é a insuficiência deste modelo de leitura escalar do mundo que dissocia as escalas e assim "autonomiza" processos e atores (fazendo com que processos e atores locais sejam separados de outros que são chamados de nacionais ou globais, por exemplo). A própria ideia de escala precisa passar por uma revisão. A escala é uma construção social a partir de relações de poder - ela é contêiner de poder. Nesse sentido, a escala, como instrumento heurístico, nos permite distinguir níveis de análise do real, mas, no real, tais níveis não são níveis, mas sim simultaneidades nas temporalidades - dos atores sociais, dos objetos e das ações que constroem o espaço geográfico.

O que justifica as narrativas escalares é, na verdade, a constatação de que os fenômenos, como simultaneidades interligadas, têm impactos, efeitos, em distintos âmbitos ou recortes espaciais. Local, regional, nacional e global estão no mesmo lugar, de modo que os elementos (atores, processos, fenômenos, objetos) sejam multiescalares e que uma escala sofra influência de fenômenos em outras escalas. Esta é a mágica (e, a importância) da organização escalar das relações políticas: ela permite que atores, relações, processos e fenômenos que coexistem no espaço sejam ordenados, de modo a estabilizar sistemas de dominação e poder. E isso vale tanto quando se pensa a escala enquanto instrumento heurístico (que explica o mundo, mas que sustenta a valorização diferenciada do global sobre o local, do universal 
sobre o particular, e consequentemente, daquilo que alguém quer afirmar como global/universal e aquilo que este alguém quer afirmar como local/particular ${ }^{3}$ ), quanto organização de experiências vividas de indivíduos, grupos e atores sociais, que são hierarquizados - e incluídos ou excluídos em jogos de poder ${ }^{4}$.

A escalaridade dos jogos políticos tem relação, portanto, com a hierarquização de atores sociais, de arenas das quais estes participam, de contextos de interação que servem ou não como arenas. Obviamente, de legitimações e exclusões que são impostas a atores sociais em cada "escala", compreendida então como um jogo de poder ordenado, com abrangência espacial definida, com atores reconhecidos (e outros não), com regras próprias e normas de conduta, com objetos de disputa específicos. Um ator global é aquele reconhecido globalmente por outros atores, que provoca

${ }^{3}$ Ver Boaventura de Souza Santos (2004). Importante aqui é acompanhar a discussão sobre o eurocentrismo e a geopolítica do conhecimento, trazida, dentre outros, por Walter Mignolo (2003), que mostra como a tensão multiescalar entre projetos globais e histórias locais se constitui num totalitarismo epistêmico intrínseco à colonialidade do saber e do poder. Mignolo mostra que o projeto moderno-colonial-eurocêntrico, ao instaurar - em muito, através da Ciência - a primazia de um sistema heurístico baseado na dualidade universal-particular, instituiu também as universalidades possíveis, relegando pouco espaço para o reconhecimento de outras conformações discursivas em todas as escalas. Revela, assim, o caráter territorializado das epistemes que, ao negar a universalidade daquilo que até então era considerado universal (o primado do olhar do homem europeu e branco), abre a possibilidade da valorização e emergência de lutas sociais ancoradas no discurso de uma outra política.

${ }^{4}$ É neste sentido que Santos (2011) aponta "a constituição de escalas como um problema de coordenação de relações, ou, de instauração de ordenamentos espaço-tempo enquanto conjuntos coerentes de objetos e ações, que podem estar distantes entre si na superfície terrestre e adjacentes a outros objetos e ações que não participam dos mesmos ordenamentos, ou seja, em situação de 'desencaixe', não tendo suas dinâmicas reguladas pelos mesmos processos. Neste sentido, um elemento no espaço pode na verdade ser integrante de uma ordem espaço-tempo (escala) e estar adjacente (ou, para utilizar a terminologia de Giddens, em plena relação de 'presença') a outro pertencente a uma outra ordem espaço-tempo. Devemos ressaltar que sua contiguidade, evidentemente, pode lhe imputar influências, comandos de algum tipo, que 'podem agir para sustentá-los ou para solapá-los', ou não. Quando ocorre algum tipo de influência entre elementos integrantes de distintas ordens espaço-tempo, optamos aqui por chamar 'fricção espaço-temporal interescalar', para apontar um ruído, uma perturbação 'inesperada' numa ordem, transgredindo assim as mediações estabelecidas por um zoneamento do tempo-espaço sobre o fluxo das práticas sociais rotinizadas" (p. 120). 
desdobramentos globais, tem condições de dialogar e impor seus projetos em âmbitos que outros não conseguem. A despeito disso, o que vem sendo cada vez mais evidente é que atores sociais "confinados" em escalas locais ou nacionais vêm aprendendo a manipular e utilizar esta forma de organização escalar de jogos de poder. É assim que surgem expressões como jumping scales (SWINGUEDOW, 1997), desencaixes e reencaixes (GIDDENS, 1991), ligações não previstas ou curto-circuitos (SILVEIRA, 1999) e boomerang effect ${ }^{5}$, por exemplo.

A multiplicidade de termos mostra a diversidade de formas como atores sociais subalternos utilizam as "escalas da política" para fazer uma "política de escalas". Quando se fala, então, de ativismos transfronteiriços ou transnacionais, devemos pensar que isto é mais do que "ir além" do nacional, articulando-se diversas escalas (nacional, global, regional, local), mobilizar outros atores, recursos (financeiros, jurídicos etc.) e processos alocados num ordenamento escalar de poder.

No caso da emergência da temática racial no Brasil, propomos aqui que o melhor é pensar em uma "política de escalas" do Movimento Negro, visto que, em diferentes momentos e espaços, é ele quem tem o protagonismo na construção, manutenção e imposição da agenda. Não há pressões internacionais, nem intranacionais, mas sim a mobilização de recursos e processos pelo movimento social em diferentes escalas e o uso de processos - também em diversas escalas - como justificativa para o fortalecimento da agenda racial pelo Movimento Negro. A riqueza de pensar em "política de escalas" é que tal conceito permite juntar numa mesma leitura a complexidade dos jogos políticos organizados de forma multiescalar e o realce ao protagonismo do movimento social que cria e mantém a agenda no debate público e nas esferas de coordenação social.

Observamos que grande parte das políticas públicas iniciadas na primeira década do século XXI já era objeto de reivindicação e luta do Movimento Negro há muito tempo (como veremos adiante o exemplo da Lei no 10.639, que obriga a inserção da temática racial e das lutas dos negros no currículo escolar) e que, inclusive, algumas delas já vinham sendo implementadas por prefeituras e governos estaduais em décadas anteriores.

${ }^{5}$ Efeito Bumerangue (Boomerang Effect) ou pressão indireta são conceitos que Keck e Sikking (1998, apud SMITH, 2005) usam ao se referirem a situações nas quais grupos dentro de um contexto político repressivo forjam alianças com atores transnacionais que podem exercer pressão sobre o Estado através de instituições internacionais. 
Diante disso temos que questionar qual o papel, o protagonismo interno do Movimento Negro em suas diversas escalas - local, regional, nacional diante das dinâmicas globais de difusão de políticas, abrangendo também as de diferença e o multiculturalismo apontados por Bourdieu e Wacquant como instrumentos do imperialismo cultural estadunidense através das fundações e agências de cooperação e fomento.

\section{2 - A emergência da "raça" na agenda educacional no Brasil: o papel do Movimento Negro em diferentes escalas}

A inserção da temática racial como base para políticas educacionais nos últimos dez anos se transformou em tema de discussão nacional. Algumas políticas, como as de cotas para ingresso de negros em universidades, geraram uma das discussões mais polêmicas em todo o país. Dentro de um marco de políticas contra o racismo e seus impactos, que incluem a criação em 2003 de um ministério para a igualdade racial e nos anos seguintes mais de uma centena de órgãos municipais e estaduais com formato semelhante, o campo que mais se destaca é a Educação. Há políticas raciais na saúde, direitos humanos, mercado de trabalho, planejamento urbano, valorização de patrimônio histórico, entre outros. Mas, a educação é o campo de maior profundidade.

As duas principais áreas das recentes políticas de combate ao racismo no sistema educacional são as de (i) acesso à educação superior e (ii) combate ao racismo no sistema escolar. Em relação ao acesso de afrodescendentes à educação superior, desde 2003 há universidades públicas adotando políticas de cotas raciais na admissão de estudantes, o que inclusive foi tornado lei para as universidades federais em 2012 (Lei ${ }^{\circ}$ 12.711). Além disso, o Ministério da Educação criou um programa de bolsas para estudantes negros em universidades privadas ${ }^{6} \mathrm{e}$ já houve, nos três níveis do poder executivo (federal, estadual e municipal), diversas iniciativas de apoio financeiro para cursos preparatórios aos exames vestibulares voltados para estudantes negros e carentes. Também merece menção a iniciativa do Ministério da Educação de apoiar grupos de pesquisa universitários que trabalham temas relacionados à temática racial, através dos editais UNIAFRO. No tocante ao combate ao racismo no sistema escolar e nas

\footnotetext{
${ }^{6}$ Estas bolsas do programa PROUNI, segundo a página do Ministério da Educação, já beneficiaram, de 2005 até o final de 2013, um total de 1.920.312 estudantes de baixa renda, dos quais $49,8 \%$ são negros (pretos e pardos).
} 
instituições educacionais em geral, foi criada a Lei $n^{\circ} 10.639^{7}$. Esta Lei, que modificou a Lei de Diretrizes e Bases da Educação Nacional (principal marco legislativo da educação no Brasil, promulgada em 1996), obriga à inclusão de temas relacionados a raça, às histórias e culturas africanas e afro-brasileiras; e de aspectos das contribuições das lutas do Movimento Negro Brasileiro na história do Brasil, além da inclusão do Dia da Consciência Negra no calendário escolar.

A construção dessa agenda envolve lutas históricas do Movimento Negro Brasileiro em diferentes escalas espaço-temporais e também processos e atores internacionais no período recente da história do país. Tentaremos aqui fazer um breve giro por estes processos multiescalares.

\section{1 - Emergência de aspectos raciais na agenda pública no contexto de novas relações entre Estado e Sociedade Civil}

A emergência de raça como base para a construção de políticas públicas pode ser vista, de um lado, como parte do processo de transformações nas relações entre Estado e Sociedade Civil. Desde a década de 1970, a sociedade brasileira experimentou um processo de redemocratização política do país, que culminou na transição do regime militar à democracia formal em 1985. Desde o fím da ditadura militar e início do processo de democratização a necessidade de formar coalizões sociais como alternativas às forças hegemônicas tornou possível a emergência de diversas lutas sociais. Novos movimentos sociais foram organizados, outros mecanismos foram criados para representar setores da sociedade civil dentro da estrutura do poder executivo (BURITY, 2006, p.70) e, enquanto algumas demandas sociais começaram a encontrar uma ambiência para a criação de políticas públicas, novas agendas trazidas pelos movimentos sociais foram incorporadas pelas esferas do Estado.

Além do fortalecimento da democracia, a década de 1990 na América Latina foi marcada na esfera econômica pelo aprofundamento da revolução técnica e científica, pela globalização e pela difusão do ideário e das políticas neoliberais. Nesta disputa é importante reconhecer a presença e influência de organizações regionais e internacionais. Durante este período as reformas educacionais foram marcadas pelo alinhamento com a agenda neoliberal, na qual descentralização, avaliação, ênfase no mérito e o fortalecimento da

${ }^{7}$ Esta Lei foi aprovada em janeiro de 2003 pelo presidente Luis Inácio Lula da Silva. 
propriedade privada e dos papéis do mercado tomaram um lugar importante (FRIGOTTO, 2003; FRIGOTTO e CIAVATTA, 2003; SARUBI, 2005).

A prescrição neoliberal em tal período também envolveu a criação de canais para o diálogo e participação da sociedade civil, que possibilitou o estabelecimento de tensões e a abertura para agendas de movimentos sociais (BURITY, 2006). É importante mencionar aqui que tal contexto também tornou possível para o Estado reconhecer não somente as agendas dos movimentos sociais, mas também os acúmulos e "competências" deles (e de seus ativistas), suas experiências e conhecimentos sobre as temáticas pelas quais lutavam, e que isso poderia ser utilizado na formulação, implementação e avaliação de novas políticas. Consequentemente, como parte das estratégias da dominação por forças hegemônicas conservadoras, uma esfera social de coordenação estatal foi fortalecida ${ }^{8}$.

Neste período, marcado por profundas disputas entre projetos e pela desconfiança por parte de um significativo número de atores sociais que lutavam no campo educacional (sindicatos, movimentos sociais, comunidade escolar, entre outros), é quando a preocupação com a temática racial emerge - o que fez parecer para alguns militantes da Educação que ela advém como mais um item do receituário neoliberal, reforçando reações à agenda racial.

Este múltiplo reconhecimento do movimento social pelo Estado (em relação às agendas e à sua expertise) permite a inserção de quadros desses movimentos em funções junto ao Estado - inclusive de assessoria parlamentar. Ainda que, em grande medida, tenha se dado de maneira intermitente e mediada pela fragilidade política, institucional e financeira contexto no qual diversas políticas são geradas e implementadas - a passagem de alguns militantes das lutas sociais pelo aparelho de Estado promove uma qualificação dos seus quadros, que vão gradativamente aprendendo a lidar com a burocracia estatal e a transitar pelos meandros institucionais e políticos da formulação de políticas públicas 9 .

\footnotetext{
${ }^{8}$ Interessante leitura crítica de tal esfera de coordenação nos é oferecida por Costa e Madeira Filho (2007), que apontam tais arenas como uma estratégia de "neocolonização democrática".

${ }^{9}$ Interessante também é a visão sobre este quadro/processo de aprendizagem e qualificação da militância, narrado por Ivair Augusto Alves dos Santos (2006) ao analisar a criação e o funcionamento, nos anos 80, do Conselho de Participação e Desenvolvimento da Comunidade Negra no Governo do Estado de São Paulo.
} 
No caso do Movimento Negro, Jaccoud (2008) aponta para o fato de que a criação de conselhos estaduais e municipais para lidar com questões da população negra e desigualdades raciais a partir dos anos 1980 serviu, então, como agenciadora desta relação entre o Movimento e o Estado ${ }^{10}$. Segundo a autora, a implantação dos conselhos constituiu uma primeira geração de políticas de ação afirmativa no Brasil e teve grande influência sobre as experiências que a seguiram até culminar na profusão que houve na década de 2000 (com a Lei n ${ }^{\circ} 10.639 / 2003$, por exemplo).

\section{2 - Processos inerentes ao Movimento Negro que levaram ao foco na criação de políticas}

A leitura do papel do Movimento Negro brasileiro na emergência de políticas públicas baseadas em raça requer um olhar sobre as mudanças nas relações entre Estado e sociedade, mas também a consideração de processos inerentes ao próprio Movimento. Dois destes processos serão destacados nesta seção: a mudança nas formas de ação social coletiva e a redefinição de prioridades e focos hegemônicos na luta antirracismo.

A dinâmica do Movimento Negro tem como marca a multiplicidade das formas de ação, pois ele congrega: entidades de caráter político, mas também social e outras de caráter cultural; entidades formalmente instituídas e outras sem institucionalização; indivíduos e grupos agindo pela luta antirracismo dentro de outras entidades e lutas (como sindicatos, partidos políticos de diferentes matrizes ideológicas, movimentos sociais, igrejas, etc., às vezes constituindo coletivos reconhecidos pela entidade, às vezes de maneira mais informal); coletivos diversos (de estudantes, de mulheres, de juventude, etc.); indivíduos atuando de maneira mais permanente, e às vezes sistemática, pela igualdade racial em seus locais de trabalho a partir de suas posições institucionais (como os ativistas dentro de universidades); indivíduos discutindo e propondo em seus ambientes de socialização, entre outras. Em um olhar sobre o Movimento Negro brasileiro não se pode, portanto, confundir "movimento" com "entidade" - ainda que em diversos momentos tenha havido tentativas de construção de uma entidade nacional que reunisse todas as iniciativas, como o Movimento Negro Unificado (MNU) e a Coordenação Nacional de Entidades Negras (CONEN).

\footnotetext{
${ }^{10}$ Jaccoud (2008) registra experiências em Minas Gerais, São Paulo, Rio Grande do Sul, Mato Grosso, Bahia, Distrito Federal, Santa Catarina, Piauí e diversas capitais, como São Paulo, Belém, Vitória, Rio de Janeiro e Belo Horizonte.
} 
Lembramos que, conforme aponta Santos (2011), movimento social é uma forma específica de ação social, mas que em seu seio mistura diferentes formas de ação (individual e coletiva).

Essas múltiplas formas se articulam e dialogam em várias espacialidades: há entidades e articulações locais, regionais, nacionais e supranacionais; há atores que participam de associações em diversas escalas, há atores - individuais, coletivos, institucionalizados ou não - que dialogam com interlocutores locais, regionais, nacionais, entre outros. Num país marcado por uma estrutura político-administrativa em três níveis (federal, estadual e municipal) que não raro são transformados em quatro, cinco ou seis (por exemplo através de coordenadorias locais, órgãos de planejamento micro, meso ou macrorregionais); e com uma história marcada por um federalismo que oscila entre a centralização na união federal, a autonomia dos governos estaduais e o localismo municipalista, a espacialidade de um ator é de suma importância. Isso porque ela vai definir qual a interlocução possível, e esta faz variar correlações e possibilidades de poder - e, no caso do Movimento Negro, há indivíduos, grupos e entidades agindo e dialogando em relações de poder nas diversas escalas, do local ao supranacional ${ }^{11}$.

O Movimento Negro brasileiro, nessa leitura, aparece como uma área de movimento, um conjunto de formas de ação que constitui um campo dialógico, que se move numa direção que é fruto de posições (e, tomadas de posição) inter-relacionadas de seus atores. O conceito de área de movimento é proposto por Alberto Melucci, e, segundo Burity (2002) tenta

(...) dar concretude empírica ao estudo desses atores plurais que são via de regra descritos como movimentos sociais. As áreas corresponderiam a campos de estruturação de identidades coletivas e a espaços de recomposição da identidade (a qual estaria continuamente exposta à fragmentação na sociedade complexa). Neste caso, porém, os indivíduos e grupos encontrariam na área de movimento um espaço para

\footnotetext{
${ }^{11} \mathrm{Na}$ escala supranacional, por exemplo, podemos mencionar a articulação que realizou os Encontros de Parlamentares Negros e Negras das Américas e do Caribe em 2003 e 2004, bem como as articulações no "processo Durban" - que envolve a preparação e realização da terceira Conferência Mundial Contra o Racismo em Durban (realizada em 2001) e também o acompanhamento e avaliação da implementação de suas recomendações. Para a relação entre o "processo Durban" e o desenvolvimento da agenda racial na Educação brasileira, ver Santos e Soeterik (2010).
} 
recomporem a identidade dividida pelo múltiplo pertencimento e pelos diferentes tempos e papéis experimentados na sociedade (p. 17).

Tal leitura nos permite dar unidade analítica a todos os indivíduos e grupos que se posicionam e agem pelo combate ao racismo e que se apresentam na sociedade como negros na figura de um movimento social que é plural, chamado Movimento Negro. Portanto, cisões, diferenças (de forma de organização, de atuação e mesmo de projetos) e divergências dentro do campo devem ser lidas como diversidade na unidade. Discordamos, assim, de autores que operam com a ideia de que há, no Brasil, "Movimentos Negros". Há um Movimento que é plural, que se move nesta pluralidade e tem exatamente nela sua maior potência constitutiva, pois ela permite a capilarização do debate antirracismo em diversas arenas de construção do social.

A diversidade não impede que existam hegemonias. E, no tocante ao formato de organização da ação, chamamos a atenção para uma tendência denominada "onguização" do movimento negro, fenômeno que Silva (2004) define como sendo:

(...) uma forma de subjetivação que homogeneíza a ação, fazendo com que os mais diversos tipos de organização, não apenas as denominadas 'organizações não-governamentais', tais como entidades filantrópicas, religiosas, comunitárias e governamentais, formulem suas práticas e objetivos segundo um modelo considerado característico dessas organizações (p. $352)$.

Aqui, chamamos a atenção para o fato de que esta forma de ação se insere num processo de direcionamento da ação coletiva e de diversas formas de ativismo, que localiza na relação com o Estado a via para a realização de suas demandas e projetos/anseios. Isso cria uma cultura política que valoriza a participação e instaura uma esfera de coordenação social via redes sociais (LECHNER, 1997) diretamente relacionada à coordenação social via Estado. Permite, em nosso caso, um "encontro" do Estado Neoliberal com setores dos ativismos e movimentos sociais que cresceram na América Latina desde a década de 1960: tanto em um quanto em outro, experiências "pontuais" ou "locais" são valorizadas e são compreendidas como ações concretas contra os problemas da sociedade. Dagnino (2004) batizou tal encontro como uma "confluência perversa", que desafia as construções dos movimentos sociais e de setores transformadores da sociedade no tempo presente. 
Ainda que a tendência de enquadramento de setores do ativismo do Movimento Negro nesta forma de estruturação da ação seja passível de diversas críticas (SILVA, 2004), ela traz mudanças fundamentais para o estabelecimento das ações afirmativas na década atual. Em primeiro lugar, a "onguização" fortalece o foco de atuação antirracismo na relação com o Estado e coloca cada vez mais a construção de projetos e políticas públicas como objetivo. Em segundo, a atuação na forma de ONG "profissionaliza" setores da militância que, se de um lado passam a depender da busca de recursos para viabilizar seu ativismo, por outro adquirem aprendizados práticos sobre formulação, execução e avaliação de políticas, bem como sobre o funcionamento do Estado. Este último aspecto é fundamental, pois abre um campo de qualificação da militância permitindo que sejam formados quadros do Movimento Negro para atuar junto e dentro do Estado na medida em que este reconhece a agenda e inicia experiências de políticas de combate ao racismo. Assim, o reconhecimento da agenda se encontra com o reconhecimento da expertise, permitindo a capilarização de ativistas nos diversos espaços de formulação e execução, nas diversas esferas do Estado.

Estes processos inerentes ao Movimento Negro - a transformação das formas de ação social coletiva e a redefinição de prioridades e focos hegemônicos na luta contra o racismo - colocaram gradativamente a construção de políticas públicas no centro da luta.

\section{3 - A educação como agenda do Movimento Negro e a construção de políticas públicas}

A Educação sempre foi um campo de disputa no qual houve atuação do Movimento Negro ${ }^{12}$. Também é fato que o conteúdo da Lei $\mathrm{n}^{\circ}$ 10.639/2003 é uma reivindicação antiga deste movimento. Reivindicações semelhantes já apareciam em sua agenda de iniciativas, como a imprensa negra da década de 1930 (PEREIRA, 2007) e a Frente Negra Brasileira sobre a qual, Edson Cardoso - assessor parlamentar que milita pelo movimento negro - afirma (ALBERTI e PEREIRA, 2007, p. 431) que seu estatuto de 1931 fazia referência ao papel essencial da educação no combate às desigualdades raciais -; nas recomendações das Convenções Nacionais do

\footnotetext{
12 Para uma visão sobre esta luta, desde os tempos da escravidão até a atualidade, ver a interessante resenha feita por Cunha Jr. e Gomes (2003).
} 
Negro, da década de 1940; nas pautas do jornal Quilombo e do Teatro Experimental do $\mathrm{Negro}^{13}$; entre outras experiências.

Tal luta se intensificou após a rearticulação, dentro do processo de redemocratização no Brasil, dos ativismos sociais negros através da criação do Movimento Negro Unificado, em 1978, num quadro de enfraquecimento da ditadura militar. A década de 1980 teve um momento crucial para a ação do Movimento Negro no campo da Educação, que foi o centenário da abolição da escravatura em 1988. Ano em que as relações raciais foram problematizadas por diversas instituições e setores, como a Igreja e o Estado brasileiro $^{14}$. O centenário da aboliç̧ão permitiu que, ao se tornar tema nacional, a questão racial adentrasse o ambiente escolar, o que muitas vezes era feito através de atividades com falas de militantes do Movimento Negro. Esta capilarização social de militantes da luta antirracismo cria, talvez pela primeira vez, um cenário no qual o campo realiza ações por meio da educação, de uma só vez (e de maneira dialeticamente articulada e difusa) em todos os seus níveis e esferas de construção, desde a escola até os aparatos burocráticos de gestão, incluindo a formulação de políticas educacionais.

A ambiência que surgiu da conjuntura na qual se deu a construção da nova Constituição Federal permitiu a organização de reivindicações do Movimento Negro junto ao Estado. A agenda educacional do Movimento foi fortalecida, entre outras, na Convenção Nacional do Negro pela Constituinte $^{15}$, realizada em Brasília em agosto de 1986. Essas reivindicações foram, porém de forma muita resumida, incluídas na Constituição de 1988, artigo 242, primeiro parágrafo, como mostra a passagem "O ensino da História do Brasil levara em conta as contribuições

13 Essas experiências foram lideradas pelo intelectual e militante negro Abdias do Nascimento, nas décadas de 1940 e 1950 (ROMÃO, 2005; SALES SANTOS, 2005).

${ }^{14}$ Cabe ressalvar que tais instituições, profundamente hegemonizadas por imaginários coloniais, funcionam muito mais como arenas nas quais indivíduos e grupos (uns marcados por imaginários coloniais e outros que combatem tais imaginários) travam disputas. Nesse sentido, as lemos como instituições que são disputadas "por dentro", o que explica suas oscilações e ambiguidades no tratamento ou negação da discussão do racismo. O aprofundamento sobre o comportamento destas instituições e setores não compõe o escopo do presente artigo.

${ }^{15}$ Esta Convenção foi organizada pelo Movimento Negro Unificado (MNU), mas houve participação de várias entidades do movimento negro brasileiro, independentemente de serem filiadas ou não ao MNU. Antes do encontro nacional aconteceram vários encontros em diferentes Estados (ver ALBERTI e PEREIRA, 2007, p. 248). 
das diferentes culturas e etnias para a formação do povo Brasileiro" (BRASIL, 1988, p. 151).

Reivindicações semelhantes às da Convenção de 1986 foram mais uma vez apresentadas ao Estado brasileiro na Marcha Zumbi dos Palmares Contra o Racismo, Pela Cidadania e a Vida, realizada em novembro do ano 1995 em Brasília, que reuniu mais de 30 mil militantes do Movimento Negro de todas as regiões do país. Nessa ocasião, em resposta ao documento Programa de superação do racismo e da desigualdade racial, entregue por lideranças do Movimento Negro, o presidente Fernando Henrique Cardoso criou o Grupo de Trabalho Interministerial para a Valorização da População Negra, que recebeu a incumbência de analisar e propor políticas de combate ao racismo e às desigualdades a ele relacionadas. Santos (2005, p. 25) afirma que alguns pontos desta histórica reivindicação do movimento negro foram atendidos pelo governo brasileiro nos anos seguintes, na forma de legislações. Ele aponta, por exemplo, para a política de revisão de livros didáticos, com a eliminação daqueles que continham ou induziam à discriminação racial. É fato também que reivindicações foram parcialmente incluídas na "nova" Lei no 9.394/96 de Diretrizes e Bases da Educação Nacional aprovada em $1996^{16}$, e mais tarde no Plano Nacional de Educação (BRASIL, 2001) ${ }^{17}$.

Importante mencionar que enquanto as respostas às reivindicações do Movimento Negro na esfera federal ainda eram tímidas na década de 1990, a atuação de diferentes organizações e atores do movimento no processo de redemocratização nos anos 1980 levou alguns governos estaduais e municipais a criarem conselhos, comissões, coordenadorias e assessorias

\footnotetext{
${ }^{16}$ Assim, o quarto parágrafo do artigo 26 da LDB diz: "O ensino da História do Brasil levará em conta as contribuições das diferentes culturas e etnias para a formação do povo brasileiro, especialmente das matrizes indígena, africana e europeia" (BRASIL, 1996).

${ }^{17}$ Importante sublinhar aqui que estamos apontando o atendimento de reivindicações do movimento social na forma de criação de legislações. No campo educacional isto toca no que a literatura chama de "currículos prescritivos" - que são documentos oficiais e legislações que não necessariamente se materializam na construção efetiva dos ambientes escolares, esta, por sua vez, é lida como "currículos praticados" (OLIVEIRA, 2003). Como nenhuma lei tem aplicação automática as implementações são sempre objeto de disputas por interpretação, que podem inclusive neutralizar a sua efetivação. Ou seja, tais legislações não significam a realização plena das reivindicações do movimento no campo da educação, isso depende da continuidade da luta no campo da aplicação e implementação das legislações. A luta continua, em novas arenas.
} 
para enfrentar questões de racismo e desigualdade racial ${ }^{18}$. Jaccoud e Beghin (2002) e Jaccoud (2008) apontam para o fato de que estes conselhos e comissões de participação criaram a base de diálogo e pressão para o Movimento Negro e provocaram o surgimento, em nível federal, da Fundação Cultural Palmares em 1988. Especificamente no âmbito da Educação, a partir do final dos anos 80, políticos de diversas tendências ideológicas em diversos estados e municípios do Brasil começaram a reconhecer a necessidade de reformular as normas estaduais e municipais que regulam o sistema de ensino. Assim, mesmo antes do governo federal formular políticas nacionais a respeito, surgiram em vários municípios iniciativas em relação à proibição de livros didáticos que disseminavam preconceito e discriminação racial $^{19}$ e iniciativas em relação à inclusão de disciplinas sobre a História dos negros no Brasil e a História do continente africano nos ensinos fundamental e médio das redes estaduais e municipais $\left(\right.$ SANTOS, 2005, p. 26) ${ }^{20}$.

Este processo de diálogo, proposição e criação de políticas que se iniciou na década de 1980 foi fortalecido no período de preparação da Conferência de Durban, no qual o foco passou a ser, de maneira aguda, na construção de políticas públicas contra o racismo e contra as desigualdades raciais no Brasil.

O processo multiescalar de produção de políticas públicas de Educação no Brasil é chave para a compreensão das políticas antirracismo na década de 2000. Argumentamos aqui que, neste processo de emergência de novas formas de coordenação social (LECHNER, 1997) - no qual novas agendas são incorporadas pelo Estado - o papel protagonista do Movimento Social Antirracismo, ou Movimento Negro, é o principal responsável pela ascensão e fortalecimento de tal agenda.

18 Por exemplo no Estado de São Paulo, em 1984, foi criado o Conselho Estadual de Participação e Desenvolvimento da Comunidade Negra. A partir daí alguns Estados como o da Bahia, Rio Grande do Sul, Minas Gerais, Mato Grosso do Sul e o Distrito Federal também criaram conselhos estaduais; e as cidades do Rio de Janeiro, Belém, Santos e Uberaba, conselhos municipais similares (JACCOUD e BEGHIN, 2002, p. 16).

${ }^{19}$ Isto aconteceu, por exemplo, nos municípios de Salvador (1990), Belo Horizonte (1990), Rio de Janeiro (1990) e Teresina (1999) (SANTOS, 2005, p. 26).

${ }^{20}$ Santos (2005, pp. 26-33), oferecendo uma síntese dessas iniciativas, indica que medidas desse tipo foram tomadas no Estado da Bahia (1989) e nos municípios de Belo Horizonte (1990), Porto Alegre (1991), Belém (1994), Aracaju (1994 e 1995), São Paulo (1996), Teresina (1998), e em Brasília (1996). 


\section{3 - A emergência de políticas públicas de combate ao racismo no Brasil e a agenda global}

No Brasil existe um consenso de que o recente avanço de políticas públicas que incluem questões de raça tem uma centralidade na terceira Conferência Mundial contra o Racismo, Discriminação Racial, Xenofobia e Intolerância Correlata, ocorrida em Durban (África do Sul) em 2001. Esta linha argumentativa indica que a Conferência de Durban foi um momento no qual os Estados nacionais se reuniram com entidades da sociedade civil para discutir o racismo e foram obrigados a se posicionar sobre suas relações raciais - assim, criou-se um tensionamento do Estado brasileiro, a partir do qual emergiram políticas.

Concordamos aqui com a ideia de que a Conferência de Durban foi fundamental no processo recente de inclusão da temática racial na pauta das políticas educacionais no Brasil. Promovida pela Organização das Nações Unidas, ela foi um importante momento de discussão, em escala global, das injustiças raciais e de políticas. O que destacamos aqui, no entanto, é que os principais impactos da Conferencia na criação de políticas públicas no Brasil não estão relacionados à declaração que foi assinada pelo governo brasileiro, mas sim às ações (em diversas escalas: local/municipal, regional/estadual e nacional) levadas a cabo pelo Movimento Negro brasileiro durante o processo que envolveu a Conferência de Durban (SANTOS e SOETERIK, 2010). Argumentamos, portanto, no caso da Conferência de Durban, que houve um complexo processo multi e interescalar de fortalecimento e tensão, no qual o Movimento Negro utiliza a existência de um fato global para fortalecer e implementar sua agenda nas escalas local, regional e nacional.

Faz-se necessário, então, pensar a Conferência de Durban não apenas como um acontecimento/ evento - concebido meramente como um momento no tempo - no qual uma convenção é assinada e o Estado brasileiro cumpre as indicações do tratado internacional do qual foi signatário. Esta leitura permitiria pensar que são pressões da agenda global que fazem o Estado nacional dar início a políticas contra o racismo. Considerando o processo de preparação da Conferência de Durban e os seus desdobramentos posteriores, os presentes autores argumentam que a Conferência precisa ser compreendida para o Brasil como um processo, o qual iniciou-se antes ${ }^{21}$,

${ }^{21}$ Aqui, convergimos para a leitura que Milton Santos faz de evento: "Os eventos não se dão isoladamente, mas em conjuntos sistêmicos - verdadeiras 'situações' - que são cada vez mais objeto de organização: na sua instalação, no seu funcionamento e no respectivo controle e regulação. Dessa organização vão depender, ao mesmo tempo, a duração e a 
através de conferências regionais, uma conferência nacional e uma conferência preparatória sul-americana ${ }^{22}$. Elas foram oportunidades de articulação e fortalecimento do Movimento Negro em diversas escalas. Assim como o Estado brasileiro foi tensionado também em diferentes escalas (local/municipal, regional/estadual, além da nacional). Neste processo de articulação do movimento e pressão sobre o Estado, agendas e políticas antirracistas foram sendo construídas.

No Brasil a fase de preparação da Conferência de Durban foi marcada pela organização de movimentos da sociedade civil, pela cooperação entre diferentes setores estatais (como entre os ministérios das Relações Exteriores e da Justiça), atores da sociedade civil (movimentos sociais principalmente o Movimento Negro - e universidades, por exemplo) e os papéis de liderança sendo conferidos a novas instituições - como o Grupo de Trabalho Interministerial para a Valorização da População Negra. A

amplitude do evento. Do nível de organização depende a escala de sua regulação e a incidência sobre a área de ocorrência do evento" (2002, p. 149). Organização, funcionamento, controle, regulação, duração/ amplitude e extensão aparecem nesta abordagem enquanto propriedades intrínsecas aos eventos (consequentemente, às escalas). Eles são a própria consubstanciação do tempo e do espaço (neste, enquanto resultantes do "encontro" entre objetos e ações organizados de forma sistêmica), são a síntese resultante da experiência enquanto convergência de todos os sentidos e dimensões da mesma: o próximo e o distante no tempo (passado, presente e futuro) e no espaço (o aqui, o ali e o alhures, todas as influências espaciais), o copresente e o ausente se misturam e se sintetizam no evento. Os eventos são pensados, desta forma, não enquanto acontecimentos pontuais situados numa fração do espaço e do tempo, mas enquanto "nós" de redes de acontecimentos vinculados e interdependentes, as cadeias de interdependência espaçotemporal. Ver também, a respeito da teoria dos eventos de Milton Santos e uma discussão sobre o conceito de escala, o diálogo que realiza Santos (RE, 2011).

${ }^{22}$ Outra forma de ler a Conferência de Durban é entendê-la como parte de um processo delineado pelo "ciclo das conferências mundiais" da ONU na década de 1990 (Conferência Mundial das Nações Unidas sobre Meio Ambiente e Desenvolvimento em 1992; Segunda Conferência Mundial dos Direitos Humanos em 1993; Quarta Conferência sobre as Mulheres em 1995, entre outras). Neste processo são construídas condições políticas, jurídicas e institucionais para a criação e consolidação de canais de diálogo entre os Estados e a sociedade civil. Além disso, este ciclo fortalece gradativamente redes e articulações de ativismo transnacional e sua relação com os Estados. 
composição plural do Comitê de Preparação Nacional ${ }^{23}$ contribuiu para o aprofundamento da discussão a respeito das prioridades no Estado brasileiro em relação à Conferência. O processo de preparação dela foi visto então, por representantes de diversos movimentos sociais, como uma oportunidade única de inclusão de temas relacionados à luta contra o racismo e a discriminação e pela promoção de igualdade racial como itens prioritários na agenda política nacional.

Na escala regional-continental, a criação da Aliança Estratégica AfroLatina e Caribenha Pró III Conferência Mundial Contra o Racismo desempenhou um importante papel na fase de preparação à Conferência. Foi esta aliança que, juntamente com outras organizações, invocou a Conferência Cidadã contra Racismo, Xenofobia, Intolerância e Discriminação, ocorrida em Santiago do Chile em dezembro de 2000.

Pode-se afirmar que, em termos dos aspectos relacionados aos afrodescendentes das Américas e especificamente afro-brasileiros, a declaração e o plano final de Durban foram uma vitória. O documento final ratificou vários parágrafos acordados no encontro regional preparatório de Santiago e tornou o conceito de afrodescendente - como sendo um grupo específico de vítimas do racismo e discriminação - aceito nas Nações Unidas. Além disso, a urgência da implementação de políticas públicas para eliminar as desvantagens sociais impostas a este grupo foi reconhecida, bem como foi recomendado aos Estados e organismos internacionais que desenvolvam programas especiais direcionados aos afrodescendentes, e que recursos financeiros extras sejam dirigidos para setores como saúde e educação. No entanto, quando se questiona sobre como a Conferência vem influenciando as políticas nas escalas nacional e regional, pode-se argumentar que ela não teve um impacto direto, uma influência prática no desenho de políticas públicas, inclusive na área da educação. Isso é confirmado pela conclusão da declaração pública elaborada ao final da Conferência das Américas da Sociedade Civil, ocorrida em junho de 2008 como etapa preparatória para a Conferência de Revisão de Durban, esta, ocorrida em abril de 2009 e que teve o propósito de avaliar o cumprimento da Declaração da Conferência de 2001:

Sete anos após a aprovação da Declaração e Programa de Ação de Durban, a despeito dos esforços da sociedade civil e de

${ }^{23}$ No Comitê havia partidos políticos, representantes do governo e de organizações não governamentais. Ele foi coordenado pela Secretaria de Direitos Humanos da Presidência da República. 
alguns Estados na região, ainda não há institucionalmente nem os necessários recursos financeiros para implementar as iniciativas estabelecidas para combater o racismo e todas as formas de discriminação (DECLARACIÓN DE LA SOCIEDAD CIVIL DE LAS AMÉRICAS DE CARA A LA CONFERENCIA MUNDIAL DE REVISIÓN DE DURBAN, 2008, p. 1).

Portanto, a influência dos processos globais no reforço da agenda antirracismo na escala nacional, indicando uma centralidade das tensões globais como determinantes da emergência de tais políticas no país, com destaque para a Conferência de Durban, nos parece insuficiente. Assim, ao analisarmos o argumento de que as políticas de ação afirmativa no Brasil são fruto de cópia ou importação de uma agenda, ou mesmo resultado do "imperialismo estadunidense" - conforme mencionamos no início deste artigo -, acreditamos que se falha na própria observação do papel dos organismos internacionais (por exemplo, o Banco Mundial) na criação de políticas baseadas em raça no nosso país. Se podemos perceber que organismos supranacionais difusores de uma agenda neoliberal nos anos 1990, na mesma década começam a expressar um crescente interesse pela ênfase em políticas sociais compensatórias ou focalizadas especialmente em educação (BURITY, 2006; ROCHA, 2006; ALMEIDA, 2008), constataremos que os discursos dessas instituições permaneceram dominados pelo pensamento desenvolvimentista sem engajamento ou protagonismo na criação de propostas de transformação mais efetivas no campo da educação.

A inclusão de clivagens sociais como as desigualdades raciais no discurso desenvolvimentista pode ser identificada em alguns documentos do Banco Mundial, como nos The Costs of Discrimination in Latin America (1994) e Brasil: Justo, Competitivo e Sustentável (2002). Nestes documentos o órgão reconhece a existência do racismo na sociedade brasileira como "explicação mais provável" (p. 89) da situação desprivilegiada de negros considerando o acesso à educação, emprego e moradia. Questionando abertamente a ideia de o Brasil ser uma "democracia racial", os documentos chegam a sugerir um diálogo com o Movimento Negro brasileiro (ou, ao menos, com ideias expressadas por ele).

Porém, reconhecendo o fato de que a preocupação com tais clivagens étnico-raciais, desde os anos 1990, vem crescendo na agenda de organismos internacionais como o Banco Mundial, devemos observar que a razão destacada nas análises e propostas sobre esses temas é econômica: 
investimento e "desenvolvimento" são as metas fundamentais. Assim, temas como a educação, não são em primeira instância discutidos como direitos, mas sim como investimento que gera capital humano e social. Consequentemente, os temas de raça e etnia passam a ser inseridos nas discussões sobre desenvolvimento e redução da pobreza. Nos documentos desses organismos o foco econômico orientado ao "investimento" pode ser percebido: exclusão étnica/racial, racismo e discriminação, quando aparecem nos dois documentos do Banco Mundial supracitados, são discutidos como "perdas de capital humano" - e não como crimes ou, ao menos, antíteses de justiça social. Por exemplo o Banco Mundial (1994) afirma que uma questão importante é analisar, para a avaliação da necessidade de criar políticas compensatórias,
(...) o quanto o grupo majoritário também sofre um "custo" quando existe discriminação contra um grupo minoritário. Quando o grupo majoritário é muito grande em comparação com o grupo minoritário, então a discriminação pelo majoritário tende a rebaixar os ganhos do minoritário. Mas, quando o grupo minoritário é uma fração de proporção importante, então a discriminação pelos membros do majoritário prejudica a eles também (BECKER, 1993, p. 20).

Acreditamos que esse tipo de análise é a explicação central por trás da preocupação dos organismos internacionais em relação às desigualdades raciais. Especialmente no Brasil, onde a população não-branca é praticamente a metade da população total e a discriminação - segundo essa teoria - prejudicaria nitidamente o crescimento econômico do país. Não surpreendentemente, então, no caso brasileiro, o Banco Mundial identifica tal tema como sendo "claramente uma área prioritária de pesquisa" (1994, p. 20).

Interessante é que, enquanto o mesmo estudo (BANCO MUNDIAL, 1994 , p. 5) aponta para o fato de que o mero "investimento" em políticas de educação (universalistas) não seria suficiente para erradicar a exclusão racial no Brasil $^{24}$ (um argumento que implica que políticas de ação afirmativa poderiam ser necessárias), as políticas e medidas recomendadas parecem

\footnotetext{
${ }^{24}$ Numa comparação entre o Brasil e outros cinco países escolhidos da América Latina, foi apontado que "para o Brasil, as diferenças salariais entre homens brancos e não brancos permanecem mesmo quando ponderadas as variáveis educação e experiência estimada (WEBSTER e DWYER, 1988). De fato, as diferenças de rendimento entre os dois grupos aumentam nos extratos de maior escolaridade" (BANCO MUNDIAL, 1994, p. 18).
} 
negligenciar (ou, se contrapor a) esta análise. Isso é ilustrado, por exemplo, pelos argumentos do Banco formulados contra as políticas de cotas raciais para as contratações feitas em alguns órgãos federais no final dos anos 90 e as propostas para o uso desse tipo de política nas admissões às universidades que circulavam nessa época:
(...) essas cotas apresentam no mínimo duas desvantagens: a primeira refere-se à reação e à polarização que podem produzir, causadas pela "discriminação inversa"; a segunda diz respeito ao teste racial de difícil aplicação no Brasil, uma vez que a sociedade não está dividida entre categorias sociais baseadas em raça como em outros países (BANCO MUNDIAL, 2002, p. 90).

Setores influentes do governo brasileiro neste período (do final dos anos 1990 ao início do século atual), como por exemplo o ministro da Educação (na ocasião, Paulo Renato de Souza), defenderam posições similares contra as políticas de ação afirmativa. $\mathrm{O}$ argumento dominante no governo e nos conglomerados midiáticos de massa era que a solução para o problema das desigualdades raciais em Educação deveria se dar através de políticas que visassem fortalecer o sistema público de educação básica no geral, e não por meio de políticas focadas em raça, como as $\operatorname{cotas}^{25}$.

Esta primeira análise da temática da desigualdade racial em educação enquanto agenda global nos indica que o reconhecimento deste tipo de disparidade e do racismo são crescentemente presentes em documentos de organismos internacionais, desde os anos 1990, e que uma mobilização

${ }^{25}$ Deve-se mencionar que os argumentos apresentados pelo Banco Mundial contra as cotas são dois dos mais utilizados até o presente nos discursos dos grupos contrários à criação de políticas de combate ao racismo baseadas em raça (FERES, 2004). Também referente ao período citado, Almeida (2008) discute a criação do programa Diversidade na Universidade e argumenta que o processo de criação, implementação e posterior desenvolvimento deveria ser compreendido no contexto dos discursos defendidos pelo governo de Fernando Henrique Cardoso naquele momento; e também por organismos internacionais como o Banco Interamericano de Desenvolvimento, entidade que financiou o programa. O autor aponta que em tal contexto o Programa poderia ser compreendido como uma forma de "concessão" do Governo, pressionado pelas reivindicações históricas do Movimento Negro por implementação de ações afirmativas (como as cotas) e as fortes resistências existentes em setores da sociedade, no próprio Governo e nos organismos internacionais, contrários a este tipo de política (ver também MOHELECKE, 2002). 
global sobre tais discussões se configurou em torno da Conferência de Durban em 2001. Nesse sentido, a inclusão de recortes étnico-raciais na agenda global poderia ser compreendida no contexto de um tensionamento internacional, no qual tais organismos internacionais, assim como os Estados nacionais, foram obrigados a se posicionar de alguma forma. No entanto, demonstramos aqui que agendas emanadas destas "dinâmicas globais" apresentam predominantemente propostas e considerações políticas que se encaixam nos discursos sobre "desenvolvimento" e "redução da pobreza" (ROCHA, 2006; ALMEIDA, 2008) e, assim, raramente consideram as raízes das causas desses tipos de exclusão - ou, soluções para elas. Enquanto essas organizações parecem desempenhar em alguns casos um "papel burocrático" (por exemplo, através de financiamento ou coordenação de eventos) em relação às iniciativas que visem fortalecer a inclusão de recortes raciais na agenda, elas não exercem protagonismo político. A abordagem desses organismos, nitidamente, não envolve uma reflexão sobre qual é (ou, poderia ser) um modelo de desenvolvimento partindo dos "aspectos sociais".

Argumentamos, desta forma, que se torna insuficiente, no caso da ascensão de políticas de combate ao racismo e às desigualdades raciais em Educação no Brasil, afirmar que são tensões da agenda política global que determinam tal percurso no país. Podemos dizer que processos globais, antes de serem algo surgido "de fora para dentro", são eles próprios resultantes da articulação de lutas dos movimentos sociais, que os provocam, constroem, mobilizam seus interlocutores (dentre os quais, os Estados) para produzir repercussões de suas lutas. Assim, podemos compreender o caso da Conferencia de Durban, construída e utilizada pelo ativismo do movimento social, no caso o Movimento Negro brasileiro. Ao tentar entender o complexo processo multi e interescalar em torno da formação de agendas e da inclusão de recortes raciais na educação no Brasil, observamos que o papel decisivo não é exercido na escala internacional, mas sim nas escalas local e nacional - num processo estimulado primariamente pelas ações do Movimento Negro brasileiro.

\section{4 - Conclusão}

Tentamos mostrar neste artigo que a emergência da raça como base para políticas públicas (e, em particular, no campo da Educação) no Brasil é fruto de um processo complexo que envolve condições, oportunidades e protagonismos políticos na luta por direitos em diversas escalas. O debate que trouxemos - pensando a complexidade dos processos mutiescalares de 
definição de agendas, repensando o próprio conceito de escala e a relação entre escalas da política - nos permite identificar três raciocínios distintos nos entendimentos sobre escalas e a ação de movimentos sociais:

a) O global condicionando o local (atores globais, interesses globais) - neste raciocínio as pautas raciais são fruto de novos imperialismos ligados à "onda neoliberal", que tem como arautos/protagonistas as agências multilaterais. Tal leitura informa uma série de interpretações da construção das políticas educacionais nos anos 1990 no Brasil (e na América Latina). E o multiculturalismo; a valorização da diferença (diferencialismo), da temática e das políticas de identidade e de raça seriam, então, fruto de uma onda que vem de fora (fora \& dentro, global \& nacional, diversos pares opositores aparecem).

b) $\mathrm{O}$ movimento implanta a sua agenda manipulando a construção de agendas e processos políticos em diversas escalas - ou seja, opera uma "política de escalas". Esta leitura aponta para uma radicalidade do protagonismo do movimento na construção de tais agendas educativas.

c) O local se beneficia de um contexto global. Esta leitura diria que há um protagonismo forte do movimento, mas a construção efetiva das políticas só se torna possível em um contexto global que se instaura (e que não é construído exclusivamente pelo movimento) e que potencializa a luta do movimento. Portanto, se não fosse o contexto e os atores globais o movimento talvez não conseguisse construir a pauta como agenda pública de políticas educativas.

Argumentamos que esse movimento social utiliza uma "política de escalas" aproveitando oportunidades abertas pelos processos globais: uma mobilização de instrumentos de pressão ao Estado para a construção de políticas (organizações internacionais, convenções e leis internacionais, eventos, processos políticos globais etc.). Nesta leitura, as relações entre processos "nacionais/locais" e "globais" não são unidirecionais ("de cima para baixo" ou "de baixo para cima"), nem dissociados (como em "níveis"), mas entrelaçamentos de tensões entre agências de disputa política, em que a simultaneidade dos processos complexifica o impacto nas diferentes escalas. Assim, se torna difícil falar de um processo de fatos "sucessivos", no qual uma construção nacional impacta a construção global, ou vice-versa. Há processos multiescalares, a um só tempo nacionais e internacionais, que se desenvolvem simultaneamente nas várias escalas.

Mostramos também que quando se refere a multiescalaridade na compreensão dos processos ligados ao Movimento Negro brasileiro não se 
está falando apenas de nacional e global, mas também de processos locais e regionais (intranacionais) que são escalas e arenas nas quais o movimento disputa. A complexidade organizativa do movimento social que mostramos é a única forma de compreender esta multiescalaridade.

\section{Bibliografia}

ALBERTI, V.; PEREIRA, A. A. (Orgs.) (2007) Histórias do Movimento Negro: depoimentos ao PDOC, Rio de Janeiro, Pallas.

ALBUQUERQUE, S. J. (2008) Combate ao Racismo. Brasília: Fundação Alexandre de Gusmão.

ALMEIDA, N. P. (2008) Diversidade na universidade: O BID e as políticas educacionais de inclusão étnico-racial no Brasil. Dissertação (Mestrado em Antropologia Social) - Programa de Pós-Graduação do Museu Nacional, Universidade Federal do Rio de Janeiro, Rio de Janeiro.

BANCO MUNDIAL. (2002) Brasil: Justo, Competitivo e Sustentável Contribuição para debate. Banco Mundial.

BOURDIEU, P.; WACQUANT, L. (2002) Sobre as Artimanhas da Razão Imperialista. Estudos Afro-Asiáticos, vol. 4, nº 1: 15-33.

BRASIL (1988) Constituição, 1988), Constituição da República Federativa do Brasil. Brasília: Senado Federal. Disponível em: $<$ http://www.senado.gov.br/sf/legislacao/const/>. Acessado em 14 mai. 2010.

BRASIL (1996) Lei nº 9.394, de 20 de dezembro 1996. Diário Oficial União. Brasília, DF. Disponível em: <http://www.planalto.gov.br/ccivil_03/LEIS/19394.htm>. Acessado em 27 abr. 2010.

BURITY, J. A. (2001) Identidade e múltiplo pertencimento nas práticas associativas locais. Série Textos para Discussão, $\mathrm{n}^{\circ}$ 108. Recife: Fundação Joaquim Nabuco.

. (2006) Reform of the State and the New Discourse on Social Policy in Brazil. Latin American Perspectives, ${ }^{\circ}$ 33. pp. 67-87.

COSTA, M. A. N.; MADEIRA FILHO, W. (2007) Externalidades Negativas: estratégias públicas e privadas de intervenção na dramaticidade social no estado do Pará, Brasil. Notícias del CeHu: Octubre. Disponível em: http://elistas.egrupos.net/lista/encuentrohumboldt/archivo/indice/2201/msg 12264/ consulta em 22/11/2011. 
DAGNINO, E. (2004) Construção democrática, neoliberalismo e participação: os dilemas da confluência perversa. Revista Política \& Sociedade, $\mathrm{n}^{\mathrm{o}} 5$, out.

DECLARACIÓN DE LA SOCIEDAD CIVIL DE LAS AMÉRICAS DE CARA A LA CONFERÊNCIA MUNDIAL DE REVISIÓN DE DURBAN. (2008) Brasília, 13 a 15 jun. Disponível em: http://servindi.org/actualidad/4192.

FERES, J. J. (2004) Ação Afirmativa no Brasil: fundamentos e críticas. Econômica, v. 6, n 2. pp. 291-312.

FRIGOTTO, G. (2003) Educação e a crise do capitalismo real, 5 ed. São Paulo, Cortez.

FRIGOTTO, G.; CIAVATTA, M. (2003) Educação básica no Brasil na década de 1990: subordinação ativa e consentida a lógica do mercado. Educação e Sociedade, vol. 24, nº 82 (abril). pp. 93-130. Disponível em: http://www.cedes.unicamp.br. Acessado em 19 abr. 2010.

GIDDENS, A. (1991) As consequências da modernidade. São Paulo: EDUNESP.

JACCOUD, L. B.; BEGHIN, N. (2002) Desigualdades raciais no Brasil: um balanço da intervenção governamental. Brasília: IPEA.

JACCOUD, L. (2008) O combate ao racismo e à desigualdade: o desafio das políticas públicas de promoção da igualdade racial'. In: THEODORO, M. (org.). As políticas públicas e a desigualdade racial no Brasil: 120 anos. Brasília: IPEA.

LECHNER, N. (1997) Tres formas de coordinación social. Revista de la Cepal, no 61, abril: 7-17.

MIGNOLO, W. (2003) Histórias locais /projetos globais: colonialidade, saberes subalternos e pensamento liminar. Belo Horizonte: Editora UFMG. MOEHLECKE, S. (2002) Ação Afirmativa: história e debates no Brasil, Cadernos de Pesquisa, $\mathrm{n}^{\circ}$ 117, novembro. pp. 197-217. Disponível em: http://www.scielo.br/scielo.php?script=sci_arttext\&pid=S01001574200200 0300011\&lng=en\&nrm=iso.

OLIVEIRA, I. B. (2003) Currículos praticados: regulação e emancipação no cotidiano escolar. Texto apresentado na $26^{\circ}$ Reunião anual de ANPEd, Poços de Caldas, 2003. Disponível em: www.anped.org.br.

PATRINOS, Harry Anthony. (1994) The Costs of Discrimination in Latin America. Banco Mundial. 
ROCHA, L. C. P. (2006) Políticas Afirmativas e Educação: A lei 10639/0 no contexto das políticas educacionais no Brasil contemporâneo. Dissertação (Mestrado em Educação) - Programa de Pós-Graduação em Educação e Trabalho da Universidade Federal de Paraná, Curitiba.

SANTOS, B. S. (2004) Para uma sociologia das ausências e uma sociologia das emergências. In: (org.) Conhecimento prudente para uma vida decente: um discurso sobre as ciências revisitado. São Paulo: Cortez. SANTOS, I. A. A. (2006) O movimento negro e o Estado (1983-1987). São Paulo: Prefeitura de São Paulo.

SANTOS, M. (2002) A natureza do espaço. São Paulo: Editora da Universidade de São Paulo.

SANTOS, R. E. (2011) Movimentos sociais e geografia: sobre a(s) espacialidade(s) da ação social. Rio de Janeiro: Ed. Consequência.

SANTOS, R. E.; SOETERIK, I. M. (2010) Brazilian Civil Society in Global Politics? The Durban Process and its Effects on the Anti-Racist Education Agenda in Brazil. Paper presented at seminar Civil Society Advocacy and Education For All, AISSR. Amsterda: University of Amsterdam.

SANTOS, S. A. (2005) A Lei 10.639/2003 como fruto da luta antiracista do Movimento Negro. In: Educação Antiracista: caminhos abertos pela lei Federal n. 10.639/903. Brasília: Ministério da Educação.

SARUBI, E. R. (2005) A gestão democrática da educação no Brasil: alguns apontamentos. Revista eletrônica Trabalho e Educação em Perspectiva. Disponível

<http://www.fae.ufmg.br/cadernotextos/backup/artigos/artigoVIII.pdf>. Acessado em 21 abr. 2010.

SILVA, A. C. C. (2004) Agenciamentos coletivos, territórios existenciais e capturas uma etnografia de movimentos negros em Ilhéus. Tese (Doutorado em Antropologia Social) - Museu Nacional, Universidade Federal do Rio de Janeiro, Rio de Janeiro.

SILVEIRA, M. L. (1996) Escala geográfica: da ação ao império? In: $O$ Discurso Geográfico na Aurora do Século XXI. Florianópolis: Programa de Pós-Graduação em Geografia, Universidade Federal de São Carlos, mimeo. SMITH, J. (2005) The uneven Geography of Global Civil Society: National and Global Influences on Transnational Association. Social Forces, vol. 84, $\mathrm{n}^{\circ} 2$, december.

SWYNGUEDOUW, E. (1997) Neither Global nor Local: Glocalization and the politics of scale. In: Spaces of globalization: reasserting the power of the 
GEOgraphia - Ano. 17 - Nº33 - 2015

local. (org.) Cox, Kewin, New York/London: The Guilford Press. pp. 137166.

Data de submissão: 14/12/2014.

Data de aceite: 08/03/2015. 